little volume ("A Year in Manitoba, 1880-8I") is published by Messrs. W. and R. Chambers, and contains a full and concise statement of the experience of an officer and his sons on a small farm which they took, about ten miles from Winnipeg. There were not a few hardsbips certainly, and these are clearly brought out ; but the other side is quite as clearly and fairly stated, with a considerable balance in its favour. For any one contemplating emigration to the Canadian North-west, this is the book to get.

BESIDES Mr. O'Neill's paper on his three months' journey inland from Mozambique, the April Proceedings of the Geographical Society contain a résumé of the information just laid before Parliament on the subject of the Russo-Persian frontier east of the Caspian, accompanied by a map, which can only pretend to reproduce the Russian view of the question. The other paper describes the journey of a Russian officer from Geoktepeh to the Khivan oasis, and is a translation from the Russian. Perhaps the most notable matter in the geographical news is the treaty which $M$. de Brazza imposed on the native chiefs at Stanley Pool, and by which they undertook to admit none but Frenchmen; some late news is also given respecting Dr. Junker's journey in Central Africa, and Mr. J. M. Schuver's progress to the south-west of Abyssinia. We are glad to see, too, that the international polar meteorological expeditions are not neglec' ed, some very interesting information being funnished respecting those of the Danes to Gudsbaab, in West Greenland, and of the Dutch to the mouth of the Yenissei, A note is also devoted to the recent Danish explorations at Mear, the Jacobshavn fjord. The French Geographical Society's meetings are very fully reported, as, indeed, they generally are.

A NEW Geographical Society was formed last month at Greifswald, in Pomerania.

A CORRESPONDENT points out, in reference to Dr.. Rae's correction of last week, that a gold medal was awarded to Nain Singh in 1877 , as will be found by reference to the Fournal for that year, or in the Proceedings (old series), vol. xxi. A gold watch bad previously been awarded to Nain Singh in 1868 , for his route-survey from Lake Mansarowar to Lhasa.

Mr. R. ARTHIngton, of Leeds, who is well-known as the munificent benefactor of African mi : ions, has just presented to the Baptist Society a further sum of 1000 . towards the cost of building a steamer for the Upper Congo.

THE Constantine gold medal of the Russian Geographical Society was not awarded this year; the medal ot Count Lutke was awarded to Major-General Ernfeldt and Col. Lebedeff, for their geodetical and topographical work in the Balkan Peninsula; the great gold medal of the Ethnographical Section was awarded to M. Potanin for his explorations in North-Western Mongolia; that of the Statistical Section to M. Romanoff for his work on emigration from the Government of Vyatka. The small gold medals were awarded to the astronomer, F. F. Schwartz, the well known explorer of Eastern Siberia, for his

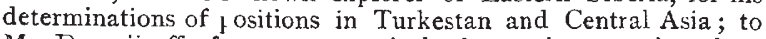
M. Domojiroff, for anemometrical observations on board of ships; to M. Mialah hoff, for etbnographical explorations on the Ural ; and to M. Yadrintseff, for his work, "Travels in Western siberia and on the Altai." Silver medals were aw arded to Mydame L. Poltoratzkaya, for her album of photographs from Western Siberia ; to M. Lakhmæyer, for photographs of Caucasus and Ural; to M. Kalitin, for maps of the route between Kbiva and Akhal-Teke; to M. Ivanoff, for explorations of the Zerafshan glacier; to M. Agapitoff, for explorations of the black earth and luess, in the Government of Irkutsk ; to M. Roubach, for meteorological observations on the island of Oesel; to M. Zagursky, fur his works on the Catcasian languages and his biography of the well.known explorer of these langnages, $R, K$. Uslar ; and to MM. Stevanovsky and Rudinsky, for collections of Russian songs.

THE last number of the Izvestix of the Russian Geographical Society contains, among other interesting nuaterials, two lists of points whose latitudes and longitudes were determined by the indefatigable explorer of Eastern Siberia and Turkestan, F. F. Schwartz, the Dorpat astrononier, during the years I879 and 1880. After baving determined, in 1879 , the positions of ten points in Eastern Turkestan, he now publishes a list of twenty. four points in the Kulja territory, from Kulja along the two long valleys of the Kash and of the Kunghes rivers, which cross this territory from east to west, that of Kunghes baving been ex- plored to its source, and the most eastern point reached by $M$. Schwartz being the Narat Pass, at the south-eastern frontier of the Kulja territory. A series of determinations between Vernyi and the Narat Pass, along the Tekes river, were made during the same year. The numerous magne' ic observations made by M. Schwartz during these two journeys, will be published as soon as calculated.

\section{MATTER AND MAGNETO-ELECTRIC ACTION ${ }^{1}$}

$\mathrm{T}^{\top \mathrm{HE}}$ late Prof. Clerk Maxwell, in his work on " Electricity and Magnetism" (vol. ii. p. I46), lays down as a principle that " the mechanical force which urges a conductor carrying a current across the lines of magnetic force, acts, not on the electric current, but on the conductor which carries it. If the conductor be a rotating disk or a fluid it will move in obedience to this force, and this motion may or may not be accompanied with a change of position of the electric current which it carries, But if the current itself be free to choose any uath through a fixed solid conductor or a network of wires, then, when a constant magnetic force is made to act on the systeri, the path of the current through the conductors is not permanently altered, but after certain transient phenomena, called induction currents, have subsided, the distribution of the current will be found to be the same as if no magnetic force were in action. The only force which acts on electric currents is electromotive force, which must be distinguished from the mechanical force which is the subject of this chapter."

In the investigation on electric discharges, on which $\mathrm{Mr}$. Moulton and myself have been long engaged, we have met with some phenomena of which the principle above enunciated afforas the best, if not the only, explanation. But whether they be r. garded as facts arising out of that investigation, or as experimental illustrations of a principle laid down by so great a master of the subject as Prof. Clerk Maxwell, I have ventured to hope that they may possess sufficient interest to form the subject of my present discourse.

The experiments to which I refer, and of which I now propose to offer a summary, depend largely upon a special method of exciting an induction-coil. This method was described in two papers, published in the Philosophical Magazine (November, 1879), and in the Proceedings of the Royal Society (vol, $x x x$. p. I 73), respectively; but as its use appears to be still mainly confined to my own laboratory, and to that of the Royal Institution, I will, with your permission, devote a short time to a description of it, and to an exhibition of its general effects.

The method consists in connecting the primary circuit directly with a dynamo-or magneto-machine giving alternate currents. In the present case, I use one of M. de 'Meritens' excellent machines driven by an Otto gas-engine. The speed of the de Meritens machine, so driven, is about 1100 revolutions fer minute.

In this arrangement the currents in the secondary are of course alternately in one direction and in the other, and equal in strength; so that the discharge appears to the eye, during the working of the machine, to be the same at both terminals.

The currents in the primary are also alternately in one direction and in the other, and consequently, at each alternation, their value passes through zero. But they differ from those delivered in the primary coil with a direct current and contact breaker in an important particular, namely, that while the latter, at breaking, fall suddenly from their full strength to zero, and then recommence with equal suddenness, the former undergo a gradual although very rapid change from a maximum in one direction through zero to a maximum in the opposite direction. The ordinary currents with a contact breaker would be represented by a figure of this kind,

while those from the alternate machine approximately by a curve of the fnllowing form. The rise and fall of the latter are, however, sufficiently rapid to induce currents of high tension and of great quantity in the secondary.

From these considerations it follows : first, that as the mackine effects its own variations in the primary current, no contact breaker is necessary; secondly, that as there is no sudden rupture of current, there is no tendency in the extra current to produce a spark or any of the inconveniences due to an abrupt opening of the circuit, and consequently that the conden er ${ }^{I}$ Lecture at the Royal Institution, March ${ }_{3} \mathrm{I}$, byoDr. W. Spottiswoode, Pres.R S. 
may be dispensed with; thirdly, that the variations in the primary, and consequently the strength and period of delivery of the secondary currents is perfectly regular; fourthly, that the strength of the currents in the secondary is very great. With a 26-inch coil by Apps I have obtained a spark about 7 inches in length, of the full thickness of an ordinary cedar pencil. But for a spark of thickness comparable at least with this, and of 2 inches in length, an ordinary 4 -inch coil is sufficient.

Owing to the double currents, the appearance of the discharge is that of a bright point at each terminal, and a tongue of the yellow flame, such as is usually seen with thick sparks from a large coil, issuing from each. This torrent of flame (which, owing to the rapidity with which the currents are delivered by the machine, is apparently continuous) may be maintained for any length of time. The sparks resemble those given by my great coil (exhibited in this theatre on Friday, April 13, 1877, and described in the Philesophica! Magazine, I877, vol. iii. p. 30) with a large battery-power and with a mercury break; but with that instrument it is doubtful whether such thick sparks could be produced at short intervals, or in a rapid shower, as in this case.

In order to contrast the effects of the two methods, I will excite the coil, first with a battery, and secondly with the alternating machine. You will notice that with the battery we can obtain either lono, bright, and thin sparks, or short and comparatively thick discharges; but, unless the latter are made very short, they occur only at couparatively long and even perceptible intervals of time. On the other hand, with the alternate machine, although the method does not lend itself so readily to the production of long and bright sparks, we can produce a perfect torrent of discharges more rapid and more voluminous than by any other means yet devised. Long bright sparks can, however, be obtained by interrupting the flow of the currents from the machine, and by allowing only single currents to pass at comparatively long intervals. It may be interesting to know that the number of currents given out by the machine, and consequently the number of discharges issuing from the coil, is no less than 35,200 , that is, 17,600 in each direction, per minute. The number may be determined by the pitch of the note which always accompanies the action of an alternate machine.

A comparison of the two methods may also be made when a Leyden jar is used as a secondary condenser. This application of the jar is well known as a valuable aid in spectroscopic research; and the employment of the alternating machine so materially heightens the effects that, judying from some experiments made in the presence of Mr. Lockyer, and from otbers of a different character in the presence of Prof. Dewar, I am led to hope from it a further extension of our knowledge in this direction. In order that you may form, at all events, some rough idea of the nature of such discharges, I venture, at the risk of causing some temporary inconvenience from the noise, to project the spectrum of this spark.

I will detain you with only one more instance of comparison. The ordinary effect of an induction coil in illuminating vacuum tubes is well known. The result is usually rather unsteady. Several instruments have been devised to obviate this inconvenience, e.g. the rapid breakers described in the Proceedings of the Royal Society (vol. xxiii. p. 455, and vol. xxv. p. 547), or the break called the "Tremblenr" of Marcel Deprez (see Comptes rendus, I88I, I. Semestre, p. I283). The use of the alternating machine, however, not only gives all the regularity in period, and uniformity in current, aimed at in these instruments, hut also at the same time supplies currents of great strength. The result is a discharge of great brilliancy and steadiness, and it is perhaps not too much to say that the effects are comparable to those obtained with $\mathrm{Mr}$. De La Rue's great chloride of silver battery. The configuration of the discharge produced in this way can also be controlled by a suitable shunt applied to the secondary circuit; for example, one formed by a column of glycerine and water, or the one consisting of a film of plumbago spread upon a slab of slate, constructed by my assistant, Mr. P. Ward, and here exhibited.

One test of the strength of current passing through a tube is the amount of surface of negative terminal, which it will illuminate with a bright glow. I have here a tube with terminals, in the form of rings, each of which would be regarded of ample size for currents obtaided in the ordinary way. These are now all connected together so as to form one grand negative terminal; and it will be found that with the currents from the alternate machine, the whole system is readily illuminated at once.
It should perbaps be here remarked that, while the strength of the secondary currents passing through the tube is partly due directly to the strength of the primary currents from the machine, it is probably also in part due to the rapidity with which the secondary currents foll ow one another. Owing to the latter circumstance the column of gas maintains a warmer and more conductive condition than would prevail if the inteval between the discharge was longer; and in consequence of this a larger portion of the discharges can make its way through than would otherwise be the case.

Before leaving the instrumental part of my discourse, I desire to bring under your notice a modification of the machine which we have thus far used for producing, by the intervention of the induction coil, currents of high tension. This consists of a machine of the same general construction as the other, but having the armatures wound with a much greater number of convolutions of much finer wire. 'The result is a machine giving off currents of sufficient tension ito effect, by direct action, discharges through vacuum tubes, and even in air. The currents are of course olternate; but by diminishing the size of one of the terminals to a mere point, as well as by other methods described elsewhere, it is possible to shut off the currents in one direction, leaving only those in the other direction to discharge themselves through the tube. I hope on some future occasion to give a fuller account of this remarkabfe machine, which has only quite recently been completed.

Returning to the discharge in air, it will be noticed that when the terminals are set horizontally, the torrent of thick discharges assumes the appearance of a flame, which takes the form of an inverted V. This is the result of convection current; due to the heat given off by the discharges themselves. The discharges are by their nature, as it were, fixed at each end, but within the limits of discharging distance, free to mive about and to extend themselves in space, especially in their central part. Further, it may be observed that the length of the spark which can be maintained is greater than that over which it will leap in the first instance. The explanation of this is to be sougint in the fact, that when the sparks follow very rapidly in succession, the whole path of each discharge remain; so far in a heated state, as to assist the passage of the next; and, further, that in the middle part of the discharge or apex of the $\Lambda$, where the heat is greatest, the heat prevails to such an extent as to render a portion of the path highly conductive. This may be illustrated by holding a gas jet near the path of the discharge. The flames will then leap to the two ends of the jet, which will perform the part of a conductor; and the real length of the discharge will be that traversed from terminal to terminal, minus the length of the intervening flame. The permanently heated part of the flame will act in the same manner in extending the effective length of the discharge.

The discharye which we are now examining is not homogeneous throughout, but consists of more than one layer. The flame, which, from the fact of its forming the outer sheath of the discharge, is the most prominent feature, consists mainly of heated but solid particles emanating from the terminals. That this is the case may be inferred in a general way from the colours which the flame assumes when different substances are placed upon the terminals; - for example, lithium or sodium. The spectrum of the flame appears to be always continuous. A convenient substance to affix to the terminals is boron glass, on account of the brilliancy to which it gives rise in the discharge; this will enable us to project the phenomenon. Within this sheath of flame, the discharge consists of the ink light characteristic of arr, and in the centre of all the true bright spark. There is reason to think that, under certain circumstances, there are more liyers to be seen; but the above division is sufficient for our present purpose. In this somewhat complicated struc. ture, the pink light corresponds to the arc, and the flime to ${ }^{\circ}$ similar accompaniment which is seen playing about the upper carbon in electric lamps when a current of great strength is used.

From this account of the methods here employed I now turn to the main question. In the inv sstigation, to which allusion was made at the beginning of this lecture, it occurred to us that an examination of the effects of a maynetic field on discharges of this character throu gh air or other gases at atmospheric pressure, and a comparison with those obtained at lower pressures, might throw some fresh light on the nature of electrical discharges in general. It is these phenomena to which I now propose to ask your attention. 
When the discharge, originally in the form of a vertical spindle, is submitted to the action of a magnet whose poles are horizontal, it spreads ont into two nearly semicircular disks, one due to the discharges in one direction, and the other to those in the opposite direction. As the magnetism is strengthened, the flame retreats towards the edge of the disks, and ultimately dis. appears. The disk then consists mainly of the pink discharge ; but with a still stronger magnetic field, it is traversed at intervals by bright semicircular sparks at various distances from the centre. In every case, bright sparks pass directly between the terminals at the opening of each separate discharge.
In order further to disentangle the parts of this phenomenon, recourse was hid in the original experiments to a revolving mirror. The light in the disks is insufficient to allow of a projection of the effects, but the accompanying diagrams represent the appearances seen in the mirror. Fig. I shows the arrangement of the terminals and the magnetic poles; Fig. 2 the appearance of the discharges in a plane at right angles to that of Fig. I ; Fig. 3 the appearance of three successive discharges (in the same direction) with a weak magnetic field and a slowly revolving mirror; Fig. 4 the same, with a slightly more rapid rate of revolution; Fig. 5 a single discharge, with a

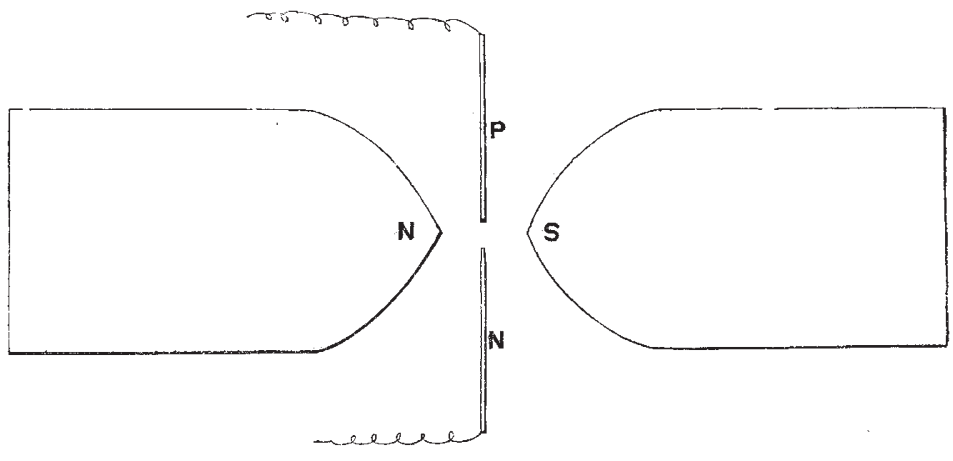

FIG. I.

stronger field and greater speed of mirror; Fig. 6 a single dis. charge in a strong field, with a still greater speed of mirror. It should be mentioned, that in all these figures the images to the left are to be regarded as anterior to those on the right, and that they represent various phases of the left-hand discharge in Fig. 2.

If, however, we observe the right-hand discharges with a mirror revolving in the same direction as before, it is clear that the actial curvature of the discharge will be turned in the opposite clirection (with reference to the motion of the mirror) to that

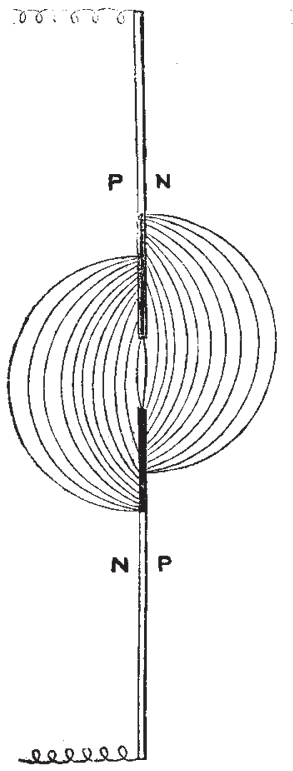

F1G. 2.

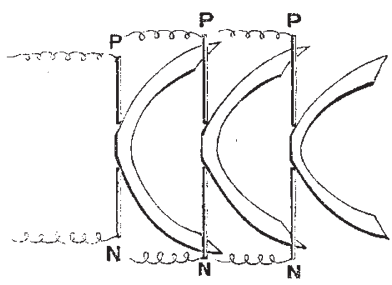

FIG. 3.

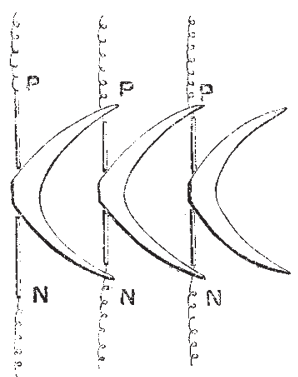

FIG. 4 . in the case of the left-hand discharges. The consequence will be, that the appearance. in the mirror, when the rate of revolution is not too great, will be something like Fig. 7, instead of Fig. 6. As the speed of the mirror is increased, the convexity will diminish, and ultimately be replaced by a concavity of the same kind, although not so marked, as that in the case of the left-hand discharges.

These diagrams show that each coil discharge commences with a bright spark passing directly between the terminals; that this spark is, in general, followed by the pink light or arc discharge, which passes first in the immediate neighbourhood of the initial spark, and gradually extends like an elastic string in semicircular loops outwards; and that the flame proper is a phenomenon attendant on the close of the entire discharge. It should be added that observations with a mirror revolving on a horizontal axis, and with a horizontal slit in front of the discharge, show that the disk is not simultaneously illuminated throughout, but that it is a locus of a curvilinear di icharge which moves outwards and expands in its dimensions from the centre.

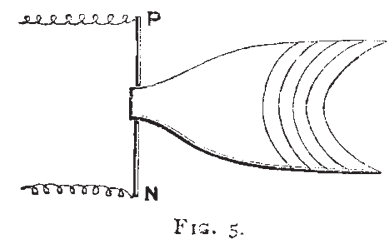

The mechanism of the discharge would therefore seem to be as follows:- In the first place, as soon as the tension is sufficient, the electricity from the terminals breaks through the intervening air, but with such rapidity that the fracture is like that of glass, or other rigid substance. This opens, a path, along which, if there remains sufficient electricity of sufficient tension, the discharge will continue to flow. During such continuance the gas becomes heated, and behaves like a conductor carrying a current, and upon this the magaet can act according to known laws. As

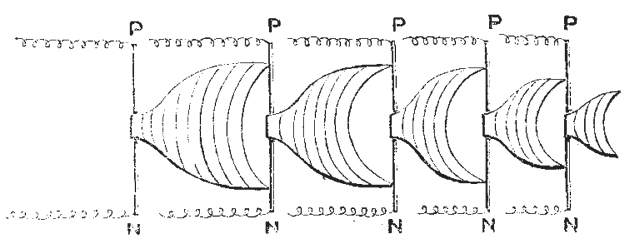

Fig. 6

long as the electricity continues to flow, the heat will at each moment determine the easiest, although not the shortest path for its subsequent passage. In this way the gas, which acts at one moment as the conductor of the discharge, and at the next as the path for it, will be carried further and further out, until the supply of the electricity from the coil fails, and the whole dis. charge ceases. We are, in fact, led by these experiments to the conclusion that it is the gas in the act of carrying the current, and 
not the current moving freely in the gaseous space, upon which the magnet acts.

This explanation of the magnetic displacement of a discharge receives strong support from the phenomena represented in Figs. 5,6 , ard 7. The successive bright lines there shown must be due to successive falls and revivals of tension within a single coil discharge. The existence of such alternations in coil dis. charges of large quantity is ctherwise known. When the fall in temperature is such that the conductivity of the gas is insufficient to maintain the arc, the discharge can make its way through the air only by a fresh rent of the same kind as the first fracture. But how can this be reconciled with the fact that the tension can never reach its original degree, and must, on the whole, be gradually falling, and that, in addition, the paths represented by these various sparks are successively longer and longer? The answer to this question is to be found plainly written in the phenomena themselves. Any irregularity in one of these bright lines is always to be found accurately repeated in all of the same series. Now, it is scarcely to be conceived that, at successive instants of time and in different portions of space, irregularities in the discharge itself, and in the distribution of the gas, so precisely the same, would constantly and for certain recur; and we are therefore driven to the conclusion, that it is the same portion of gas which at first c ccupied the centre of the field, with its same, yet unhealed rent, which is moved outuard under the action of the magnet. If this be so, we have in this repetition of minute details, nothing more than what would necessarily follow from successive reofenings of the weak parts of the gas, which would be surely found out by the electricity in its struggle to pass.

The view here taken of the material character of the luminous discharge is further borne out by the fact that the spindle of light is capable of being diverted by a blast of air. When the blast is gentle, the discharge becomes curvilinear, approximately semicircular, and the yellow flame may be seen playing about the outer edge in the same way as in a weak magnetic field. When the blast is stronger, the sheet of light becomes irregular in form, and it is traversed by a series of bright lines, all of which follow, even in their minute details, the configuration of

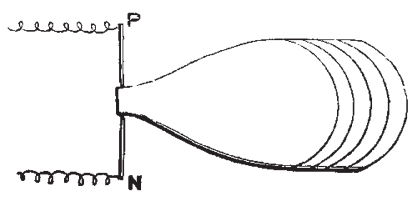

FIG. 7 .

the sheet. The analcgy between this and the phencmena-produced in a strong magnetic field needs no further remark. If the strength of the blast be still further increased, the flame and the sheet of light both disappear, and nothing remains but bright sparks passing directly, and undisturbed, between the terminals. In this case the air is both displaced and cooled so rapidly by the blast, that it no longer offers a practicable conductive path for the remainder cf the electricity, coming from the coil, to follow. Of this a succesion of disruptive sparks is a necessary consequence.

The effect thus produced by a very strong blast is in fact similar to that observed when a jar is used as a secondary condenser. In this case the electricity, instead of flowing gradually from the coil, passes in one or more instantaneous discharges with finite intervals of time between them. Each of these has to break its way through the air ; and that done, it ceases. Hence, neither a magnet, nor a blast of air will have any effect in diverting s uch a discharge.

As a last stage of the phenomena, it may be mentioned that, if the interval between the terminals be near the limit of striking distance, either a blast of air, or the setting up of a magnetic field, will alike extinguish the discharge.

Our experiments have been thus far carried on in air at atmospheric fressure; $t$ ut there is nothing in this pressure which is essential to them or to the conclusions to which we have been led. We may therefore repeat them in air, or any other gaseous medium, at any pressure we please. This consideration leads us into the region (so fertile in an experimental point of view) of discharges in vacuum tubes.

Commencing with a tube of mcderate diameter and of very slight exhaustion, we can at once recognise our former phenomena slightly changed. Proceeding to another tube, of larger diameter and of moderate exhaustion, ard placing it axially or equatorially in a magnetic field, we see not only that the dis. charge (or rather the conductor carrying it) is displaced, but also that the displaced part is spread out into a sheet or ribbon, showing that the discharge is affected gradually, exactly in the same way as was found in the open air.

When the exhaustion is carried further, the phenomena become rather more complicated. At an early stage there is a distinct separation between the "negative glow" and the rest of the luminous column; and at a more advanced stage the column itself is broken into separate luminosities or striæ. When this is the case, it is usually said that the negative glow follons the lines of magnetic force, while the luminous column distributes itself according to Ampère's law.

It will, however, be found that when completely analysed the action of the magnet upon the strix, taken individually, is the same as that upon the negative glow, due allowance being made for the differences in local circumstances subsisting between the one and the other. We eave elsewhere shown that the negative glow is in reality as truly a stria as any other individual member of the luminous column; but with this difference, that it is anchored to, and dependent for its form on, a rigid metallic terminal, whereas each of the others is dependent on the varial le form and position of the stria immediately next in order, reckoning from the negative end of the tube. The action of a magnet in throwing the negative glow into a sheet of light, which is the locus of the lines of force passing thrcugh the terminal, and which consequently varies with the position of the tube in the field, is a phenomenon so well known that we need repeat only a single experiment by way of reminder.

Although it is not altogether so easy to show that the other strix are directly affected by a magnetic field in the same way as is the anchored stria, we may still satisfy ourselves that it is the fact, from the consideration that $\mathrm{w}$ hen the striæ are well developed and the magnetic field is strong, it is quite possible to form a magnetic arch at any part of the column. In this exferiment it will be noticed that for the formation of the arch in mid-column it is necessary that both poles of the magnet should act upon one and the same stria. This, in fact, means that the pole nearest the negative end anchors the stria, and thereby brings it into conditions similar to those of the negative glow. When this is effected the two exhibit similar modifications in the magnetic field.

In support of this view, we may adduce another and quite independent method of anchoring a stria, and of thereby producing a magnetic arch elsewhere than at the negative terminal. It was noticed by Goldstein and others that if the negative terminal of a tube be enveloped by an insulaiing surface of any form pierced with a number of holes or if a diaphragm similarly pierced be placed anywhere in the tube, that the pierced surface will act as a negative terminal. He also found that the finer and closer the holes, the more complete the resemblance to the action of a negative terminal. But even when the substance is metallic, and when the holes are neither very small nor very numerous, a perforated diaphragm will so far act like a negative terminal as to serve as a point of departure of a stria. There is, however, this difference, that the blank space immediately adjoining the diaphragm, as it is usually called, is not generally so large as that at the true terminal; and the stria thus artificially formed always lie close up to the holes. The diaphragm, in fact, anchors the stria, and renders it susceptible of the same magnetic effect as was shown in the cases studied before.

The action of a diaphragm in a magnetic field gives rise to many other interesting and remarkable results; some of which would further illustrate the views now submitted for your consideration. But these must be reserved for another occasion.

In the foregoing experiments, and in the remarks which have accompanied them, I have endeavoured to illustrate, by reference to gaseous media, the principle enunciated at the outset, that in the displacement of the discharge in a magnetic field, the subject of the magnetic action is the material substance or medium which conveys the discharge. I have shown also that, even when the discharge takes place in media so attenuated as to produce the phenomena of striæ, the same principle applies not only to the discharge as a whole, but also to each component stria or unit; and, lastly, that the apparent diversity of effect on the various striæ is due to local circumstances, and not to any fundamental difference between the "negative glow" and the members of the " positive column."

Seeing now that the magnetic displacement of the luminous discharge means displacement of the matter in a luminous con- 
dition, and that a crowding of such luminous matter involves an increase of luminosity, may we not infer with a high degree of probability that the strix are themselves aggregations of matter, and that the dark spaces between them are comparatively vacuous.

It is true that such a view of the case would seem to imply that, in gaseous media, the better the vacuum the more easily can the electricity pass; and that this might at first sight appear to be at variance with the known fact that the resistance of a tube decreases with the pressure until a minimum, determinate for each kind of gas, and then increases. Bnt it has been sug. gested by Edlund (Annales de Chemie et de Physique, i881, to n. iii. p. 199) that the resistance of a tube may really consist of two part-, first, that due to the pa-sage of the electricity tbrough the gas itself, and, secondly, th t due to it; passage from the terminals to the gas; and also that the former decreases, while the latter increases, as the pressure is lowered. On this supposition, the observed phenomena may be explained, without assigning any $\lim t$ to the facility with which electricity may traverse the mo:t vacuous space.

We may even carry the suggestion of a resistance of the second kind a little further, and :uppose that there is a resistance due to the passage of electricity frum a medium of one density to that of another, or from layer to layer of different degrees of yressure. And from this point of view, we may regard the stria as expressions of resistance due to the varying pressure in different parts of the tube. Into the question, whence tbis variation of pressure, I am not at present prepared to enter; it must suffice for thi; evening, to have shown that the conclusions which we have drawn from our experiments, are $n$ t in di accordance with other known phenomena of the electrical discharge.

The warning hand of time bids me not to prolong my discus. sion of the subject. But before closing, I would point out that these laborat ry experiments are not unsuggestive in reference to larger questions. It has long been, and still is, a disputed question whether a display of the aurora borealis ever takes place at any considerat.le elevation above the earth's surface. On the one hand, ob ervations are cited giving a not unfrequent elevation of nearly 200 miles; while on the oth $x$, experiments with vacuum tubes appear to limit the range to less than forty miles. The observation is perhaps a doubtful one at best; it is not easy to fix the position of so faint and flickering a pheno. menon, and it is perhaps even more difficult to' identify a particular phase of it when seen from two distant positions. But the recorded data are still entitle. 7 to some consideration, especially if it has been shown that the evidence furnished by vacuum tubes is not conclusive against the higher estimate.

It would be very pleasant, if, wafted by the breezes of scientific imagination, we were to set full sail, and navigate our bark into still more distant space. And, indeed, we are under no slight obligations to the strong minds and courageous spirits who thus adventure themselves out beyond well-known waters; for the treasures which they bring back from every such voyage are both valuable and strange, and they set men thinking on new and untrodden 1 nes. But lest, less fortu ate than my neighbours in any such venture, I should fail to fall in with a returning current, capable of recovering my expended energy, and of restoring myself to terra firma, I must here pause. It is, however, said, that in the mind of every one, even the most philosophic, there is a tender part; and therefore I must ask your indulgence, if, while resolutely turning my back on physical speculations, I still return for a moment to my first love, mathetnatical contemplation. For, in the region which we have been considering, namely, the magnetic field, explored and represented by its electric action, we seein to have entered ufon a world which Riemann might have longed to see, a world wherein Lobatcheffski and Beltrami might have enjoyed the full fruition of realised ideas, and where even Clifford might have found abundant scope for the exercise of his inexhaustible powers of imagination and of thought.

\section{FLORA OF NEW SOUTH WALES IN ITS} GEOLOGICAL ASPECT

THIS, the oldest of the Australian settlements, may have its area grouped as follows:- (I) That of the sundstones or poor country represented by the Proteads and Epacrids; (2) the eastern slopes of coast range represented by the tree-nettles and the palms; (3) the cold mountain shrubsure, resented by sassa- fras, tree ferns, and myrtles ; and (4) the interior $f$ lains repre sented by Chenopods and Compositæ. It may be wondered how the distribution of the vegetation has originated. That the Australian continent has risen slowly, is gathered from numerous proofs, among others the very apparent one of the strata exhibiting preponderately a horizontal pline. It may further be inferred that in its uplifting, the outer rim of the continent was slightly more elevated than the interior. This taken into consideration along with what doubtless at one time existed, namely, a great inland $s \in a$, abundance of marshes and mud, and a once probable greater rainfall, and particularly the latter, though one and all may have contributed to the present physical features, and consequently plant life. Another interrogatory arises, viz. Whence the coal-seams? As to these, there is some likelihood they are the remains of vegetation borne hence from a now surken conti. nent eastward of Australia ; New Zealand, Norfolk, and Howes Island being outliers or now mere island vestiges of the said great land area in the Pacific Ocean.

Of the four local divisions above enumerated, the most typical vegetation of the fir $t$ is the group Proteacex, a very ancient family, extending back to the secondary period of geology, from which time Australia apparently has never been submerged. A point of very considerable importance as bearing on this longcontinued stability of the Australian continent may be derived from the remarkable cluse relationship and insensible gradation of some plants ; for instance there is great difficulty in separating species of Eucalypti, Banksias, \&c. Thus it may be said none or few of the connecting links have been lost, as must necessarily have been the case had submergence and elevation of the land have occurred.

Many curious problems yet await investigation, such as the fertilisation of the Proteads, including the Styleworts and Goodenia family. Again, have the Epacrids once been a family of trees, wherefrom the living species are but decadent examples? The Casuarinex, or Beefwod tribe, are u idoubtedly an ancient group, and like conifers, flourished in the dawn of life. The second division of the eastern sl pes, Palins, and Tree-nettles possibly may have had an Asiatic origin, through the Malayan Archipelago. They appear not to be truly Australian in origin, but themselves only lung established celonists. $O_{12}$ the costrary, among the third divi ion of the cold mountain scrub; the Dorophoræ (Sassafras) hold a con. spicuous place, and evidently are of Australian derivation. The peculiar vege ation of the interior plains or fourth division, the Chenopods and the Compositæ, are rapidly becuming one of the past, and the small species even now are sensibly giving place to the introduced grasses and weeds. Apart from the groups mentioned as most typical of the four areal divisions in question, as regards the Acacias and Eucalypt;, they have the widest distribution and complicated genera. They both appear to be genera at their zenith, having exi,ted long enough to pass into redundant forms, but not long enough to have been exposed to vicissilude; and decline. Their absence from Howe's Island and New Zealand shows they in all likelihood did not belong to the hypothetical submerged continent, nor are they old enough to be fuund along with the lanrel and other remains of the gold drift. (Abstract of a communication by Mr. Robert Fitzgerald, F.L.S., read at the meeting of the Linnean Society, February 2, I882.)

\section{UNIVERSITY AND EDUCATIONAL
INTELLIGENCE}

CAMBRIDGE.-The recent report of the Council of the Senate relative to the proposed Frosessorship of Animal Morphology, is creditable both to the University and to the Council. We think it desirable to quote some of its paragraphs entire. "The successful and rapid development of biological teaching in Cam. bridge, so honourable to the reputation of the University, has been formally brought to the notice of the Council. It appears that the classes are now so large that the acconmodation provided but a few years ago has already become insufficient, and that plans for extending it are nuw occupying the attention of the Museums and Lecture-Rooms Syndicate.

"It is well known thai one branch of this teaching, viz., that of Animal Morphology, has been created in Cambridge by the efforts of Mr. F. M. Balfour, and tla: it has grown to its present importance through his abili.y as a teacher and his scientific reputation.

"The service to the interests of natural science thus rendered 